\title{
Invasiveness of left- and right-sided infective endocarditis: Does pressure explain pathology?
}

\author{
Andrew Bridgeman, $\mathrm{MBChB}, \mathrm{BSc}$, and Umberto Benedetto, $\mathrm{MD}, \mathrm{PhD}$
}

\footnotetext{
From the Bristol Heart Institute, University of Bristol, School of Clinical Sciences, Bristol, United Kingdom. Disclosures: Authors have nothing to disclose with regard to commercial support.

Received for publication Aug 8, 2017; accepted for publication Aug 19, 2017; available ahead of print Sept 19, 2017

Address for reprints: Umberto Benedetto, $\mathrm{MD}, \mathrm{PhD}$, Bristol Heart Institute, University Hospitals Bristol, Senate

House, Tyndall Ave, Bristol BS8 1TH, United Kingdom (E-mail: umberto.benedetto@ hotmail.com).

J Thorac Cardiovasc Surg 2018;155:62

$0022-5223 / \$ 36.00$

Copyright (c) 2017 by The American Association for Thoracic Surgery

http://dx.doi.org/10.1016/j.jtevs.2017.08.051
}

Infective endocarditis (IE) is a serious condition associated with high mortality. Studies ${ }^{1,2}$ and guidelines ${ }^{3}$ have helped clinicians identify and manage patients with IE. Left- and right-sided disease variants have long been believed to represent 2 separate clinical identifies, but the reasons for each remain poorly understood.

Right-sided IE is rare in comparison with left-sided disease, ${ }^{4}$ accounting for only $5 \%$ to $10 \%$ of cases. The invasive nature of left-sided disease has been previously reported $^{5}$; however, there is little to be found in the literature comparing right- and left-sided disease and contrasting their propensities toward local invasion. Hussain and colleagues ${ }^{6}$ are to be congratulated for their report in this issue of the Journal of their experience with right-sided IE and their attempts to put forward hypotheses to explain the contrasting clinical findings observed.

In their article, Hussain and colleagues ${ }^{6}$ hypothesized the potential pathogenesis underlying the higher incidence of invasiveness of left-sided IE that is seen when comparing it with right-sided disease. They performed a retrospective observational study of 1292 patients who underwent surgery for IE and analyzed the "invasiveness" of the disease, as assessed by operative and echocardiographic findings. They found that only $0.72 \%$ of cases of right-sided IE were invasive, compared with $65 \%$ of aortic valve IE, $31 \%$ of mitral valve IE, and $67 \%$ of combined aortic and mitral valve IE. Hussain and colleagues ${ }^{6}$ conclude that "invasion and development of cavities/'abscesses' in patients with IE may be driven more by chamber pressure than organism."

It should be noted, however, that a number of factors limit the conclusions that can be drawn from these observations, many of which are noted by Hussain and colleagues ${ }^{6}$ themselves. For example, there is a lack of information regarding times between onset of symptoms, diagnosis, and intervention, which may inform the potential relationship between duration of IE (untreated) and invasiveness. Also, importantly, no information is offered regarding the associations invasiveness.

\section{References} 32:118-25. Surg. 2018;155:54-61.

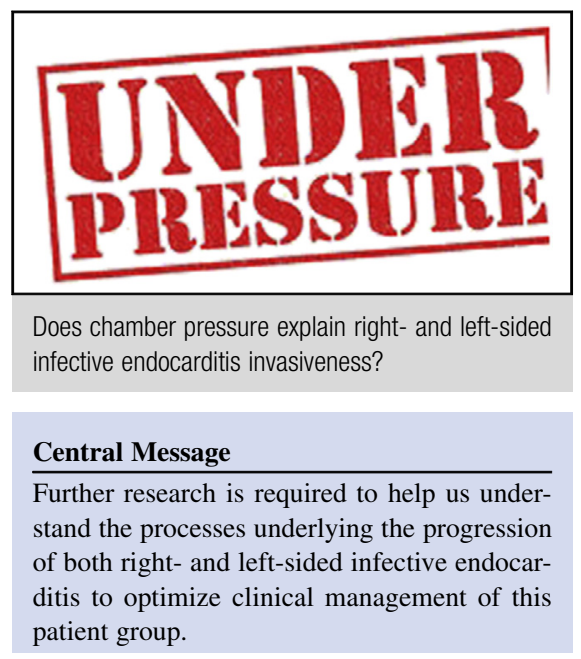

See Article page 54.

between native aortic pathology (eg, the presence of a bicuspid aortic valve or rheumatic heart disease) and baseline characteristics (eg, age, renal function, or sex) and

Further research is required, both clinical and experimental, to help us understand the processes underlying the progression of both right- and left-sided IE if we are to optimize the clinical management of this patient group.

1. Cabell CH, Abrutyn E, Fowler VG Jr, Hoen B, Miro JM, Corey GR, et al; International Collaboration on Endocarditis Merged Database (ICE-MD) Study Group Investigators. Use of surgery in patients with native valve infective endocarditis: results from the International Collaboration on Endocarditis Merged Database. Am Heart J. 2005;150:1092-8.

2. Musci M, Siniawski H, Pasic M, Grauhan O, Weng Y, Meyer R, et al. Surgical treatment of right-sided active infective endocarditis with or without involvement of the left heart: 20-year single center experience. Eur J Cardiothorac Surg. 2007;

3. Habib G, Lancellotti P, Antunes MJ, Bongiorni MG, Casalta JP, Del Zotti F, et al. 2015 ESC Guidelines for the management of infective endocarditis: The Task Force for the Management of Infective Endocarditis of the European Society of Cardiology (ESC). Endorsed by: European Association for Cardio-Thoracic Surgery (EACTS), the European Association of Nuclear Medicine (EANM). Eur Heart J. 2015;36:3075-128

4. Akinosoglou K, Apostolakis E, Marengo's M, Pasvol G. Native valve right sided infective endocarditis. Eur J Intern Med. 2013;24:510-9.

5. Hussain ST, Shrestha NK, Gordon SM, Houghtaling PL, Blackstone EH, Pettersson GB. Residual patient, anatomic, and surgical obstacles in treating active left-sided infective endocarditis. J Thorac Cardiovasc Surg. 2014;148:981-8.e4.

6. Hussain ST, Shrestha NK, Witten J, Gordon SM, Houghtaling PL, Tingleff J, et al. Rarity of invasiveness in right-sided infective endocarditis. J Thorac Cardiovasc 